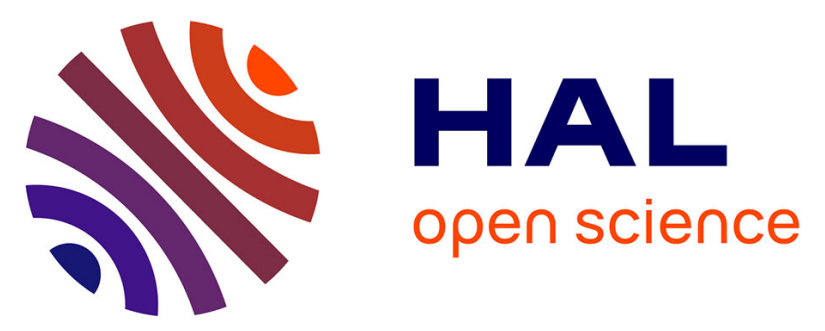

\title{
Investigation of the polyurethane chain length influence on the molecular dynamics in networks crosslinked by hyperbranched polyester
}

Przemyslaw Czech, Lidia Okrasa, Françoise Mechin, Gisèle Boiteux, Jacek

Ulanski

\section{To cite this version:}

Przemyslaw Czech, Lidia Okrasa, Françoise Mechin, Gisèle Boiteux, Jacek Ulanski. Investigation of the polyurethane chain length influence on the molecular dynamics in networks crosslinked by hyperbranched polyester. Polymer, 2006, 47 (20), pp.7207-7215. 10.1016/j.polymer.2006.05.066 . hal-02096757

\section{HAL Id: hal-02096757 https://hal.science/hal-02096757}

Submitted on 11 Apr 2019

HAL is a multi-disciplinary open access archive for the deposit and dissemination of scientific research documents, whether they are published or not. The documents may come from teaching and research institutions in France or abroad, or from public or private research centers.
L'archive ouverte pluridisciplinaire HAL, est destinée au dépôt et à la diffusion de documents scientifiques de niveau recherche, publiés ou non, émanant des établissements d'enseignement et de recherche français ou étrangers, des laboratoires publics ou privés. 


\title{
Investigation of the polyurethane chain length influence on the molecular dynamics in networks crosslinked by hyperbranched polyester
}

Przemyslaw Czech $^{1,2}$, Lidia Okrasa ${ }^{1, *}$, Francoise Méchin ${ }^{2}$, Gisele Boiteux ${ }^{2}$, Jacek Ulanski ${ }^{1}$

1. Department of Molecular Physics, Technical University of Lodz, 90-924 Lodz, Poland;

2. UMR CNRS 5627 "Ingénierie des Matériaux Polymères", Université Claude Bernard Lyon 1 and INSA-Lyon, 69622Villeurbanne Cedex, France

Corresponding author: Lidia Okrasa, Fax: (+48 42) 63132 18; e-mail: lokrasa@p.lodz.pl

\begin{abstract}
Several non-conventional polyurethane (PU) networks crosslinked with hyperbranched polyester (Boltorn ${ }^{\circledR} \mathrm{H} 40$ ) were synthesised with an aim to determine an influence of the PU chain length on molecular relaxations in such systems. The PU chain length was regulated by changing the macrodiol length or by changing the number of the repeating macrodiol/diisocyanate units $n$. Molecular dynamics were investigated by broadband dielectric spectroscopy and by dynamic mechanical analysis. It was found that the macrodiol length has a strong influence on the glass transition and the $\alpha$-relaxation, and also on the crystallization. By contrast, the changes of $n$ practically do not affect the molecular relaxations. This effect was explained by the formation of a physical network by hydrogen bonds between urethane groups, controlling the molecular mobility. The rheological measurements have shown, that at temperatures above $150^{\circ} \mathrm{C}$, when hydrogen bonds were thermally destroyed, not only macrodiol length but also $n$ had strong influence on the flowing point.
\end{abstract}

Keywords: molecular dynamics, polyurethane networks, hyperbranched polymer

Published in Polymer vol. 47, 7207-7215 (2006) 


\section{INTRODUCTION}

Polyurethanes (PUs) are unique polymeric materials with a wide range of physical and chemical properties [1]. Because many different monomers are now commercially available and tailor-made properties can be obtained from well-designed combinations of precursors, PUs can be tailored to meet the highly diversified demands of modern technologies such as coatings, adhesives, fibre, foams, and thermoplastic elastomers. Several papers published on this topic show that by changing the composition and the conditions of processing one can influence the chemical and morphological structure of PUs and their properties [2-4].

Linear segmented polyurethane elastomers can be considered as block copolymers, which consist of soft segments formed with polymer glycol and hard segments based on diisocyanate and chain extender. The properties of these PU elastomers are strongly dependent on molar mass and polydispersity of the soft segment component, as well as on the chemical structure and weight fraction of all components [5-11]. Especially, polyether polyurethanes have been intensively studied due to their excellent physical properties, resistance for infectiousness, and superior blood compatibility. An increase of the hard segment content in polyurethane structures gives polymers with higher elastic modulus. Changes of molar mass and chemical structures of the soft segments and chain extenders produce polyurethanes with modified properties $[12,13]$.

As far as the networks are concerned, one of the important factors used for changing their properties is the type of crosslinking agent. Often enough, in PU systems two kinds of networks can be present: physical and chemical. The physical network is created by the $\mathrm{H}$ bonds, which link the carbonyl groups and NH groups of adjacent chains [14]. Chemical network parameters depend on the crosslinker nature. Recently some papers dealing with the use of dendritic molecules as crosslinking agents were published [15-17].

In this work several PU networks based on hyperbranched polyester were investigated by means of broadband dielectric spectroscopy and dynamic mechanical analysis, which give complementary information about the molecular dynamics. The comparison of these two techniques and methods of analysis and comparison of their results was discussed comprehensively by Pakula [18]. The synthesised polyurethane systems were different in length of the linear chain between the crosslinking points, which was regulated by using macrodiols of different molar masses or by changing the number of repeating macrodiol/diisocyanate units in the chain. 


\section{EXPERIMENTAL}

\subsection{Materials}

Several PU networks crosslinked by the hyperbranched (HB) polyester of $4^{\text {th }}$ generation (Boltorn ${ }^{\circledR} \mathrm{H} 40$ ) were synthesized in bulk using polytetrahydrofuran (Terathane ${ }^{\circledR}$ ) with different molar masses: 650, 1000, 2000 and $2900 \mathrm{~g} / \mathrm{mol}$, and 4,4'diisocyanatodiphenylmethane (MDI with $\mathrm{M}_{\mathrm{w}}=250 \mathrm{~g} / \mathrm{mol}$ ) as monomers. The structure of the used reagents is shown in Fig. 1. According to the producer Boltorn ${ }^{\circledR} \mathrm{H} 40$ has a molar mass $M_{w}=5100 \mathrm{~g} / \mathrm{mol}$ with polydispersity $M_{w} / M_{n}=1.8$ and hydroxyl number 470-500 $\mathrm{mg} \mathrm{KOH} / \mathrm{g}$. These data give at the average 44 primary $-\mathrm{OH}$ groups in the molecule. The substrates were used as supplied by the producers without additional purification.

The aim of the synthesis presented in this paper was to obtain series of networks in which polyurethane linear chains are connected by the HB crosslinker. The PU linear chains in these series have different lengths, controlled by the molar mass (i.e. length) of the macrodiol or by the number $(n)$ of the repeating macrodiol-diisocyanate units. The constant number of primary $-\mathrm{OH}$ functions present in the $\mathrm{HB}$ polymer controls the number of $\mathrm{PU}$ chains connected to the hyperbranched polyester.

The synthesis of polyurethane was carried out in bulk. Amounts of ingredients for synthesis of stoichiometric systems were calculated in accordance to the numbers of the $-\mathrm{OH}$ groups in the $\mathrm{HB}$ crosslinker and to the projected length of the PU chains between the crosslinking centres [17].

The calculated amount of Terathane ${ }^{\circledR}$ was placed in a flask equipped with magnetic stirrer and heated up to $80^{\circ} \mathrm{C}$ and kept during half an hour under vacuum. Then the crosslinker was added and the mixture was stirred at about $100^{\circ} \mathrm{C}$ until all was dissolved. When the solution was clear, it was placed under vacuum at $60^{\circ} \mathrm{C}$ for half an hour in order to avoid bubbling during the reaction. In the next step MDI, heated up to $60^{\circ} \mathrm{C}$, was added. After quick mixing the reaction mixture was cast onto an aluminium pan and again placed under vacuum at $60^{\circ} \mathrm{C}$ for half an hour. To proceed with the full conversion of reaction the pan was placed in a drying oven at $100^{\circ} \mathrm{C}$ for 7 hours. The polymers were obtained as films with thickness from 0.2 to $1 \mathrm{~mm}$. A schematic road of the synthesis of the PU network crosslinked with the HB centres is shown in Fig. 2. The end of reaction was determined by FTIR spectroscopy. In the final PU networks the diisocyanate $-\mathrm{N}=\mathrm{C}=\mathrm{O}$ band $\left(2250-2275 \mathrm{~cm}^{-1}\right)$ was absent in the spectra. The bands characteristic for the polyurethane formations appear at: $3320 \mathrm{~cm}^{-1}$ - 
urethane $\mathrm{N}-\mathrm{H}$ stretching; $1731 \mathrm{~cm}^{-1}$ - urethane $\mathrm{C}=\mathrm{O}$ without hydrogen bonding; $1710 \mathrm{~cm}^{-1}$ urethane $\mathrm{C}=\mathrm{O}$ with hydrogen bonding; $1535 \mathrm{~cm}^{-1}$ - urethane $\mathrm{N}-\mathrm{H}$ bonding.

\subsection{Characterisation techniques.}

The chemical structure of the synthesised materials was verified by FTIR absorption using a Bio-RadFTS $175 \mathrm{C}$ spectrometer in the reflection mode with the Harrick IRS attachment.

The glass transition temperatures $\left(T_{g}\right)$ were determined using differential scanning calorimetry (TA Instrument DSC 2920). Two runs were performed for each sample in the range from $-150^{\circ} \mathrm{C}$ to $+200^{\circ} \mathrm{C}$ with a heating rate of $10 \mathrm{C} / \mathrm{min}$ under nitrogen atmosphere. The cooling scans were performed at an average rate of $25 \mathrm{C} / \mathrm{min}$. The $T_{g}$ values were determined as the onset points from the second scans with an accuracy better than $1^{\circ} \mathrm{C}$.

Molecular relaxations were characterised in broad temperature and frequency ranges by dynamic mechanical analysis (DMA) using TA Instrument DMA 2980 Dynamic Mechanical Analyser, and dielectric relaxation spectroscopy (DRS) using Novocontrol Broadband Dielectric Spectrometer. The DMA was performed in film tension mode in the temperature range from $-130^{\circ} \mathrm{C}$ up to $+150^{\circ} \mathrm{C}$ with a temperature ramp of $2 \mathrm{C} / \mathrm{min}$ using rectangular samples with the length $25 \mathrm{~mm}$, width $5 \mathrm{~mm}$ and thickness $1 \mathrm{~mm}$. Three frequencies were applied: 1,5 and $10 \mathrm{~Hz}$. The DRS was performed in the frequency range $0.01 \mathrm{~Hz}-1 \mathrm{MHz}$ and in the temperature range from $-150^{\circ} \mathrm{C}$ up to $+130^{\circ} \mathrm{C}$ with a step $5^{\circ} \mathrm{C}$ with temperature stabilisation better than $0,1^{\circ} \mathrm{C}$. For these measurements circular shape samples with diameter of $20 \mathrm{~mm}$ and thickness up to $0.5 \mathrm{~mm}$ were used.

Dielectric results were presented in the classical representation of complex dielectric permittivity $\left(\varepsilon^{*}=\varepsilon^{\prime}+\mathrm{i} \varepsilon^{\prime \prime}\right)$, as well as using the electric modulus $\left(M^{*}=M^{\prime}+\mathrm{i} M^{\prime \prime}\right)$ representation defined by Macedo et al [19]. The real $M^{\prime}$ and imaginary $M^{\prime \prime}$ parts of the electric modulus were calculated according to the equations 3 and 4:

$$
\begin{aligned}
& M^{\prime}=\frac{\varepsilon^{\prime}}{\varepsilon^{\prime 2}+\varepsilon^{\prime 2}} \\
& M^{\prime \prime}=\frac{\varepsilon^{\prime \prime}}{\varepsilon^{\prime 2}+\varepsilon^{\prime 2}}
\end{aligned}
$$

where: $\mathcal{E}^{\prime}$ and $\varepsilon^{\prime \prime}$ are, respectively, real and imaginary part of the permittivity.

Although the complex permittivity representation is easier in an interpretation, the modulus representation can be very useful, where conductivity processes are involved. 
The activation energy maps were prepared on the basis of both dielectric as well as mechanical spectra. The points were taken from the maxima of the $\varepsilon$ " $(f)$ plots using the WinFit software for the dielectric relaxations and manually from the $M$ " $(T)$ plots for the conductivity phenomenon. For the mechanical relaxations the points were taken from the $E$ " $(T)$ plots. Estimation of the position of the maxima was done with an accuracy better than $2^{\circ} \mathrm{C}$. The relaxation times $\tau$ were calculated from the equation: $\tau=1 /(2 \pi f)$, where $f$ stands for frequency.

Viscoelastic measurements were performed using a Rheometrics Instrument RS5 apparatus in the range of temperatures from $+150^{\circ} \mathrm{C}$ up to $+230^{\circ} \mathrm{C}$ and for frequencies from $10^{-2}$ up to $10^{2} \mathrm{rad} / \mathrm{s}$. The temperature step was $10^{\circ} \mathrm{C}$. Samples for these measurements had a diameter of $25 \mathrm{~mm}$ and a thickness of about $0.5 \mathrm{~mm}$. Additionally, the activation plots were prepared from the rheological results. As the characteristic parameter the flowing point, when $\tan \delta=1$, was taken.

\section{RESULTS}

The glass transition temperatures of the investigated systems determined by means of DSC are collected in Table 1, where the samples nomenclature is also defined. It appears clearly that the $T_{g}$ of the PU networks depends mainly on the length of the macrodiol used in the reaction. For the PU with longer macrodiol segments the $T_{g}$ is shifted to lower temperature. For the systems with a constant high molar mass macrodiol, Terathane ${ }^{2} 2000$, the increase of the number $n$ of repeating macrodiol-diisocyanate units from 4 to 20 practically does not influence the value of the $T_{g}$. Our previous investigations have shown that also for the samples with Terathane ${ }^{\circledR} 650$ the increase of $n$ resulted only in a slight decrease of the glass transition temperature [17]. The DSC second run spectra recorded for the systems with different lengths of macrodiol are shown in Fig. 3. Besides the steps connected to the glass transitions, for the samples with Terathane ${ }^{\circledR} 2000$ and Terathane ${ }^{\circledR} 2900$ endothermic peaks connected with the melting of polyoxytetramethylene-rich soft domains are visible at $14^{\circ} \mathrm{C}$ and $22^{\circ} \mathrm{C}$, respectively. For Terathane ${ }^{\circledR} 2000$ at $-17^{\circ} \mathrm{C}$ additionally an exothermic crystallization peak is visible. During the first heating scan, the sample is brought to an amorphous, totally disordered state. But after cooling, a partial phase separation and crystallization of the soft segments can occur [20-22], provided that they are long enough so that the steric hindrance is low and their chain ends do not constitute a too big amount of "impurities". This crystallization peak was not detected for the sample based on 
Terathane ${ }^{\circledR} 2900$, presumably because in this case the crystallization occurs so rapidly and effectively during the cooling that it is already completed, when the heating scan begins.

Fig. 4 shows the 3D frequency and temperature dependencies of the permittivity imaginary part for the samples with macrodiols of different lengths. One can see that for the samples based on short macrodiol Terathane ${ }^{\circledR} 650$ (Fig. 4a), three relaxation processes in order of decreasing temperature $\alpha, \beta$ and $\gamma$ are visible. Above the $\alpha$-relaxation, a conductivity phenomenon occurs, that is well visible in Fig. 5 showing the dielectric modulus representation. Similar relaxations are detected for the sample based on Terathane ${ }^{\circledR} 1000$ (Fig. 4b). In the case of the samples with longer macrodiols Terathane ${ }^{\circledR} 2000$ or Terathane ${ }^{\circledR} 2900$, the $\beta$-relaxation is overlapped by the $\alpha$-relaxation, which is shifted to lower temperatures (Fig. 4c, d). For the sample 20-T2000 at about $-35^{\circ} \mathrm{C}$ the frequency independent peak, labelled $\alpha^{\prime}$, is visible. The origin of this relaxation is most probably the same as that of the exothermic peak visible in the DSC diagram. This process is also visible in DMA measurements (see Fig. 5). In this temperature range, a big increase of both parts (real and imaginary) of storage modulus is observed. Such behaviour means that the sample becomes stiffer. One can conclude that at about $-35^{\circ} \mathrm{C}$ cold crystallization of polyoxytetramethylene-rich domains is initialised.

Fig. 5 shows the comparison of dielectric and mechanical moduli spectra for the samples with different lengths of the macrodiol and constant $n=20$. One can see that the position of the $\alpha$-relaxation strongly depends on the macrodiol molar mass. At $1 \mathrm{~Hz}$ the maximum of the $\alpha$-relaxation for the sample $20-\mathrm{T} 650$ is at $-28^{\circ} \mathrm{C}$ and shifts to $-44^{\circ} \mathrm{C}$ for $20-\mathrm{T} 1000,-62^{\circ} \mathrm{C}$ for 20-T2000 and 20-T2900. Positions of the $\alpha$-peak maxima in the DRS spectra correspond very well with those in the DMA spectra, where at $1 \mathrm{~Hz}$ for the sample 20-T650 the $\alpha$-process has maximum at $-25^{\circ} \mathrm{C}$, for $20-\mathrm{T} 1000$ at $-47^{\circ} \mathrm{C}$ and for $20-\mathrm{T} 2000$ at $-67^{\circ} \mathrm{C}$. One can see that change tendencies of the $\alpha$-process maximum are the same as those for $T_{g}$ determined by the DSC measurements (see Table 1). As was mentioned above, the $\beta$-relaxation is well pronounced only for the samples with Terathane ${ }^{\circledR} 650$ and Terathane ${ }^{\circledR} 1000$ and the maxima of these peaks at $1 \mathrm{~Hz}$ in DRS are at about $-90^{\circ} \mathrm{C}$. In the DMA measurements the $\beta$-process occurs in the same temperature region. The $\gamma$-relaxation is well visible for all systems. The positions of the maxima are similar for all the systems, i.e. at $1 \mathrm{~Hz}$ about $-135^{\circ} \mathrm{C}$ to $-140^{\circ} \mathrm{C}$. The data from dielectric and mechanical results are collected in the activation plots in Fig. 6. In the DMA measurement for the $20-\mathrm{T} 2000$ sample over $-20^{\circ} \mathrm{C}$ a decrease of moduli is visible. This process is connected with a partial melting of the sample, which is also detected 
in the DSC thermogram (Fig. 3). Unfortunately, the DMA measurements for the 20-T2900 sample were not possible because the sample was too soft for the experiments in tension mode.

The second way of changing the average PU chain length between the crosslinks was by increasing the number $n$ of the repeating macrodiol/diisocyanate units. For this purpose, series of samples with Terathane ${ }^{\circledR} 2000$ and $n=4,10$ and 20 were investigated. Fig. 7 shows the dielectric and mechanical spectra of the PU systems obtained from macrodiol Terathane ${ }^{\circledR} 2000$. On the DRS spectra at $1 \mathrm{~Hz}$ for all the systems two relaxation processes are visible, $\alpha$ and $\gamma$, at about $-60^{\circ} \mathrm{C}$ and $-145^{\circ} \mathrm{C}$, respectively. On the DMA spectra only the $\alpha$-relaxation can be observed. Its position for $1 \mathrm{~Hz}$ is about $-70^{\circ} \mathrm{C}$. The $\gamma$-relaxation is below the measurement temperature range. Above the $\alpha$-relaxation in the DRS spectra a small peak $\left(\alpha^{\prime}\right)$ is also present. In this range in the DMA spectra for all the samples with Terathane ${ }^{\circledR} 2000$ an increase of the shear modulus is observed, followed by a decrease above $c a-25^{\circ} \mathrm{C}$. This effect is connected with the cold crystallization and melting phenomena, as it will be discussed further on. The activation energy plots for the dielectric and mechanical measurements are shown in Fig. 8.

In Fig. 9 the results of the rheological measurements for three samples (20-T650, 20-T2000 and 4-T2000) are shown. As the characteristic parameter the flowing point (when $\tan \delta=1$ ) was taken. One can see that the viscoelastic properties of the samples differ strongly. The flowing points for the samples based on the longer macrodiol appear at much lower temperatures (or at higher frequencies) than those for the networks with the shorter Terathane ${ }^{\circledR}$. Also an increase of the number of repeating units $n$ results in a shift of the flowing points to lower temperatures (or to higher frequencies).

\section{DISCUSSION}

In all the investigated systems, two relaxation processes (primary $\alpha$-relaxation and secondary $\gamma$-relaxation) are visible in the DRS spectra. Secondary $\beta$-relaxation is detected only for the systems prepared from Terathane ${ }^{\circledR} 650$ and Terathane ${ }^{\circledR} 1000$. In the systems with longer macrodiol, the $T_{g}$ is strongly shifted to lower temperatures and the $\beta$-relaxation is overlapped by the $\alpha$-relaxation. The DMA measurements give similar results, however the $\gamma$-relaxation is below the measurement temperature range and only high temperature shoulder of this process is visible ( $c f$ Figs. 5 and 7). 
Positions of the $\alpha$-relaxation, generally associated with the glass transition and observed in both the DRS and DMA measurements are in good agreement. The $\alpha$-process is strongly sensitive on the length of macrodiol used in the synthesis of PU networks - with increasing the molar mass of the macrodiol the positions of the $\alpha$-peak and $T_{g}$ shift to lower temperature. Such effect was expected because for longer chains of macrodiol the stiffness of the system decreases and glass transition should occur at lower temperature. On the other hand increasing the PU chain length by repetition of the soft-hard chain segments should also result in a decrease of the glass transition temperature, what is not observed. Such behaviour can be due to the H-bonds, which are created between the urethane groups in the PU chains and which can superimpose additional physical network to the existing chemical network. The mean distance between H-bonds in the PU chains is mainly determined by the length of the macrodiol and due to that, an increase of the macrodiol molar mass results in significant changes of $T_{g}$. On the other hand an increase of $n$ has a much weaker influence on the concentration of the H-bonds and therefore the stiffness of the systems with different numbers of repeating units is similar.

Such effect was already reported by Nabeth et al. [23], for simpler PU networks based on polycaprolactone or poly(1,4-butanediol/1,2-ethanediol)adipate macrodiols, MDI or $\alpha, \alpha, \alpha, \alpha$-tetramethyl-m-xylylene diisocyanate and 2-ethyl 2-hydroxymethyl 1,3-propanediol (trimethylolpropane) as a crosslinker. The authors have found that for these homogeneous networks the empirical equations with a $2^{\text {nd }}$ order dependence of $T_{g}$ on the urethane weight concentration $N_{u}\left(T_{g}=T_{g 0}+\mathrm{A} N_{u}+\mathrm{B} N_{u}{ }^{2}\right)$ can be applied [23]. We have analysed in a similar way the dependence of $T_{g}$ on $N_{u}$ for the samples listed in Table 1, as well as for those described in our previous paper [17]. The $N_{u}$ values were calculated from the molar masses of the precursors and their proportions, assuming that all the $\mathrm{OH}$ and $\mathrm{NCO}$ groups had reacted together. The experimental points obtained in such a way are shown in Fig. 10. One can see that these points can be also fitted by an analogous empirical $2^{\text {nd }}$ order law: $T_{g}=-89.5+8.22 N_{u}+5.20 N_{u}^{2}$. This suggests that our networks, once above the possible partial melting of some polyoxytetramethylene-enriched domains, should be quite homogeneous and that their $T_{g}$ would be linked to the urethane concentration by a universal relationship. It is remarkable that in the cited Nabeth's work such relation was not valid for the networks with non-pointlike crosslinks obtained by free radical polymerization of acrylate chain ends, that displayed a quasi-two-phase morphology; in our case the architecture of the hyperbranched crosslinks is also complex, but nevertheless it seems to lead to a homogeneous 
structure of the global network. It is worthy to note that the value extrapolated for zero urethane groups, i.e. $-89^{\circ} \mathrm{C}$, is close to the glass transition temperature reported for high molar mass polyoxytetramethylene $\left(-84^{\circ} \mathrm{C}\right)[24]$.

The secondary $\beta$-relaxation is most probably attributed to the local motions of the polar urethane groups $[4,25,26]$. This relaxation is well visible only for the systems with the shortest macrodiol Terathane ${ }^{\circledR} 650$ and Terathane ${ }^{\circledR} 1000$, and for these systems its position is almost identical, at about $-90^{\circ} \mathrm{C}$. For the networks with Terathane ${ }^{\circledR} 2000$ and 2900 this $\beta$-process probably is also present in similar temperature range, so its position is close to the $\alpha$-relaxation, which for the networks with long macrodiols is shifted to low temperatures, and because of higher intensity overlaps the secondary $\beta$-relaxation. This overlapping is clearly visible on the activation plots for these systems (see Fig. 6).

The $\gamma$-relaxation is visible in all the investigated systems at practically the same temperatures, i.e. at ca. $-140^{\circ} \mathrm{C}$ at $1 \mathrm{~Hz}$. This relaxation is assigned to local motions of the $\left(\mathrm{CH}_{2}\right)_{4}$ sequences of the soft segments. In the investigated systems such sequences are identical; therefore the activation energies for the $\gamma$-relaxations are also similar, around $37 \mathrm{~kJ} / \mathrm{mole}$, for all the samples.

In the dielectric measurements for the samples based on Terathane ${ }^{\circledR} 2000$ above their glass transition the additional relaxation peak $\left(\alpha^{\prime}\right)$ is present. Because the position of this peak corresponds to the exothermic peak present in the DSC curves as well as to the sharp increase of the storage modulus in the DMA measurements, this process is most probably connected with cold crystallization of polyoxytetramethylene-rich domains. As discussed before, all the samples obtained from longer macrodiols (Terathane ${ }^{\circledR} 2000$ or Terathane ${ }^{\circledR} 2900$ ) are partially crystalline. The longer the macrodiol used in the reaction, the higher melting temperature is observed. This fact is proved by the DSC measurements, which show endothermic peaks at $14^{\circ} \mathrm{C}$ and $22^{\circ} \mathrm{C}$ for $20-\mathrm{T} 2000$ and $20-\mathrm{T} 2900$ samples, respectively. The melting process is not sensitive to the changes in the repeating units number $n$. For the samples with Terathane ${ }^{\circledR} 2000$ the melting process is detected also by DMA, which shows a rapid decrease of storage modulus in this temperature range.

To verify the hypothesis that dense H-bonds can determine the behaviour and properties of the investigated systems at low temperatures, rheological measurements have been performed at high temperatures. Above $c a 150^{\circ} \mathrm{C}$ the $\mathrm{H}$-bonds should be thermally destroyed and in this temperature range the behaviour of the chemical network should become evident. And indeed it was found that with increasing length of the macrodiol the samples became 
softer, and the flowing point of the system is shifted to higher frequency (or to lower temperature) range. Also in the systems differing by the number of their repeating macrodioldiisocyanate units $n$ one can see that for higher values of $n$ the flowing point is present at higher frequency (or at lower temperature). These observations confirm the hypothesis that the increase of the polyurethane length by increasing the macrodiol length or by increasing the number of repeating units makes the polymer softer at high temperatures, when destruction of the H-bonds allows to reveal such behaviour.

\section{CONCLUSION}

Molecular relaxations and properties of polyurethanes crosslinked with hyperbranched polyester (Boltorn ${ }^{\circledR} \mathrm{H} 40$ ) depend on the connecting PU chain length in different ways, depending if the PU chain length was regulated by the macrodiol (Terathane ${ }^{\circledR}$ ) length or by the number of the repeating units $n$. When the macrodiol length is increased and $n$ is constant, the glass transition and the $\alpha$-relaxation shift strongly to lower temperatures. The systems with the longest macrodiols additionally show ability for crystallization. By contrast, the changes of $n$ practically do not affect the glass transition and the molecular relaxations, if the macrodiol length is fixed. This effect is explained by a formation of the physical network by hydrogen bonds between the urethane groups, which control the molecular mobility. The rheological measurements show that at temperatures above $c a 150^{\circ} \mathrm{C}$, when the hydrogen bonds are thermally destroyed, not only macrodiol length but also $n$ have strong influence on the flowing point.

Therefore the properties of the polyurethane networks can be tailored not only by modification of architecture of the chemical network but also by changing the concentration of the urethane groups, i.e. by changing the density of the hydrogen bonds. It is possible to produce polyurethane systems showing similar properties at room or lower temperatures, e.g. similar $T_{g}$ and similar molecular relaxations, but very different behaviour at high temperatures. It is possible to control the temperature of the flowing point, what is important on the one hand from the point of view of resistance of the obtained material to high temperature, and on the other hand from the point of view of processability.

\section{ACKNOWLEDGEMENTS}

This work was supported partially by MIRA project $\mathrm{N}^{\mathrm{o}} 0200665901$ (Rhone-Alpes, France), by KBN project $\mathrm{N}^{\mathrm{o}} 4$ T08E 01223 (Poland), by Department of Molecular Physics of Technical University of Lodz (Poland) and Laboratory of Polymer Materials and Biomaterials of 
University Lyon 1 (France) in the frame of NoE "NANOFUN-POLY" 6FP EU. We thank Professor Philippe Cassagnau for help and discussion on the rheological measurements. We would like to underline an inspiring role of late Professor Tadeusz Pakula with whom we had many fruitful discussions during realization of these investigations.

\section{REFERENCES}

1. Polyurethane Handbook, Ed. Gunter Oertel, Hanser Publisher, Munich 1994.

2. Mitzner E, Goering H, Becker R. Angew. Makromol. Chem. 1994; 220: 177-188.

3. Dabdin S, Burford RP, Chaplin RP. Polymer 1996; 37: 785-792.

4. Kanapitsas A, Pissis P, Garcia Estrella A. Eur. Polym. J. 1999; 35: 923-937.

5. Petrovic ZS, Ferguson J. Prog. Polym. Sci. 1991; 16: 695-835.

6. Ng HN, Allegrezza AE, Seymour RW, Cooper SL. Polymer 1973; 14: 255-261.

7. Furukawa M, Komiya M, Yokoyama T. Angew. Makromol. Chem. 1996; 240: 205-211.

8. Koberstein JT, Russell TP. Macromolecules 1986; 19: 714-720.

9. Shirasaka H, Inoue SI, Asai K, Okamoto H. Macromolecules 2000; 33: 2776-2778.

10. Kojio K, Fukumaru T, Furukawa M. Macromolecules 2004; 37: 3287-3291.

11. Furukawa M, Hamada Y, Kojio K. J. Polym. Sci., Part B: Polym. Phys. 2003; 41: 23552363.

12. Spathis G, Niaounakis M, Kontou E, Apekis L, Pissis P, Christodoulides C. J. Appl. Polym. Sci. 1994; 54: 831-842.

13. Redman RP. In: Buist JM editor. Developments in Polyurethanes, Applied Science Publishers, London, 1978, Chap. 3.

14. Yilgör E, Yilgör I, Yurtsever E. Polymer 2002; 43: 6551-6559.

15. Rzaev ZMO, Guner A, Can HK, Asici A. Polymer 2001; 42: 5599-5606.

16. Nasar A, Jikei M, Kakimoto MA. Eur. Polym. J. 2003; 39: 1201-1208.

17. Czech P, Okrasa L, Boiteux G, Mechin F, Ulanski J. J. Non-Cryst. Sol. 2005; 35 : 2753 2758.

18. Pakula T. In: Kremer F, Schoenhals A editors. Broadband Dielectric Spectroscopy, Springer, 2003, Chap. 16.

19. Macedo PB, Moynihan CT, Bose R. Phys. Chem. Glasses1972; 13: 171-179.

20. Petrovic ZS, Budinski-Simendic J. Rubber Chem. Technol. 1985; 58: 685-700.

21. Cognet-Georjon E, Mechin F, Pascault JP. Macromol. Chem. Phys. 1996; 197: 35933612.

22. Chen WP, Frisch KC, Wong SW. Adv. Urethane Sci. Technol. 1992; 11: 110-136. 
23. Nabeth B, Corniglion I, Pascault JP. J. Polym. Sci., Part B: Polym. Phys. 1996; 34: 401417.

24. Peyser P. In Bandrup J, Immergut EH, editors. Polymer Handbook, Third Edition, John Wiley \& Sons, Inc., New York, 1989, p. VI-209.

25. Kanapitsas A, Pissis P, Gomez Ribelles JL, Monleon Pradas M, Privalko EG, Privalko VP. J. Appl. Polym. Sci. 1999; 71: 1209-1221.

26. Apekis L, Pissis P, Christodoulides C, Spathis G, Nisounakis M, Kontou E, Schlosser E, Schoenhals A, Goering H. Colloid Polym. Sci. 1992; 90: 144-150. 


\section{Figure captions}

Fig. 1. Structure of the monomers used for the PU network synthesis

Fig. 2. Diagram of the PU network synthesis

Fig. 3. DSC spectra (second scans) for the PU systems with different lengths of macrodiol: a) 20-T650, b) 20-T1000, c) 20-T2000 and d) 20-T2900.

Fig. 4. Frequency and temperature dependencies of the dielectric permittivity imaginary part for the PU networks based on macrodiol with different molecular weights, but constant $n=$ 20: a) 20-T650, b) 20-T1000, c) 20-T2000 and d) 20-T2900.

Fig. 5. DRS and DMA spectra for the PU networks based on macrodiols with different molecular weight but constant $n=20$ : 20-T650 $(\boldsymbol{\square}, \square), 20-\mathrm{T} 1000(\bullet, \bigcirc), 20-\mathrm{T} 2000(\boldsymbol{\Delta}, \triangle)$ and 20-T2900 $(\bullet, \diamond)$. Full points - real part, open points - imaginary part of the moduli.

Fig. 6. Activation map for relaxation process in the PU networks based on macrodiols with different molecular weight but constant $n=20$ : 20-T650 ( $\square, \boldsymbol{\square})$, 20-T1000 (O,•), 20-T2000 $(\triangle, \mathbf{\Delta}), 20-\mathrm{T} 2900(\diamond)$. Open points - DRS; full points - DMA.

Fig. 7. DRS and DMA spectra for PU networks based on the same macrodiol Terathane ${ }^{\circledR} 2000$ but with different numbers of repeating units $n$ : 4-T2000 $(\boldsymbol{\nabla}, \nabla), 10-\mathrm{T} 2000(\bullet, \diamond)$ and 20-T2000 $(\boldsymbol{\Delta}, \triangle)$. Full points - real part, open points - imaginary part of the moduli.

Fig. 8. Activation map for PU networks based on the same macrodiol Terathane ${ }^{\circledR} 2000$ but with different numbers of repeating units $n$ : 4-T2000 $(\nabla, \boldsymbol{\nabla}), 10-\mathrm{T} 2000(\diamond, \diamond)$ and 20-T2000 $(\boldsymbol{\Delta}, \triangle)$. Open points - DRS; full points - DMA.

Fig. 9. Rheological measurements for the samples: 4-T650 ( $\boldsymbol{\square}, \square), 4-\mathrm{T} 2000(\boldsymbol{\nabla}, \nabla)$ and 20-T2000 $(\boldsymbol{\Delta}, \triangle)$. Full points - real part, open points - imaginary part of the shear modulus $G$. Inset diagram shows the frequency-temperature dependence of the flowing points.

Fig. 10. Dependence of $T_{g}$ (determined from the second DSC scans) versus the weight concentration of the urethane groups $N_{u}$ determined for the PU networks described in this work and in ref. 17 (solid line: empirical $2^{\text {nd }}$ power law $T_{g}=-89.5+8.22 N_{u}+5.20 N_{u}{ }^{2}$ ). 
Table 1. The glass transition temperatures determined from the DSC second scans for the PU based networks crosslinked with hyperbranched polyester (Boltorn ${ }^{\circledR} \mathrm{H} 40$ ).

\begin{tabular}{|c|c|c|c|}
\hline $\begin{array}{c}\text { PU network } \\
\text { name }\end{array}$ & $\begin{array}{c}\text { Number of } \\
\text { repeating units in } \\
\text { the PU chain }(\boldsymbol{n})\end{array}$ & $\begin{array}{c}\text { Molecular weight } \\
\text { of Terathane }{ }^{\circledR} \\
\text { [g/mol] }\end{array}$ & $\boldsymbol{T}_{\boldsymbol{g}}\left[{ }^{\mathbf{}}{ }^{\mathbf{C}}\right]$ \\
\hline $20-\mathrm{T} 650$ & 20 & 650 & -43.5 \\
\hline $20-\mathrm{T} 1000$ & 20 & 1000 & -59.5 \\
\hline 20-T2000 & 20 & 2000 & -77.3 \\
\hline 20-T2900 & 20 & 2900 & -82.1 \\
\hline 4-T2000 & 4 & 2000 & -77.7 \\
\hline 10-T2000 & 10 & 2000 & -77.0 \\
\hline
\end{tabular}


Terathane $^{\circledR}$

MDI

$\mathrm{HO}^{\mathrm{CH}_{2}}{ }_{\mathrm{CH}_{2}}{ }_{\mathrm{CH}}^{\mathrm{CH}_{2}}{ }_{\mathrm{mH}}^{\mathrm{O}}$

\section{Boltorn ${ }^{\circledR} \mathrm{H40}$}

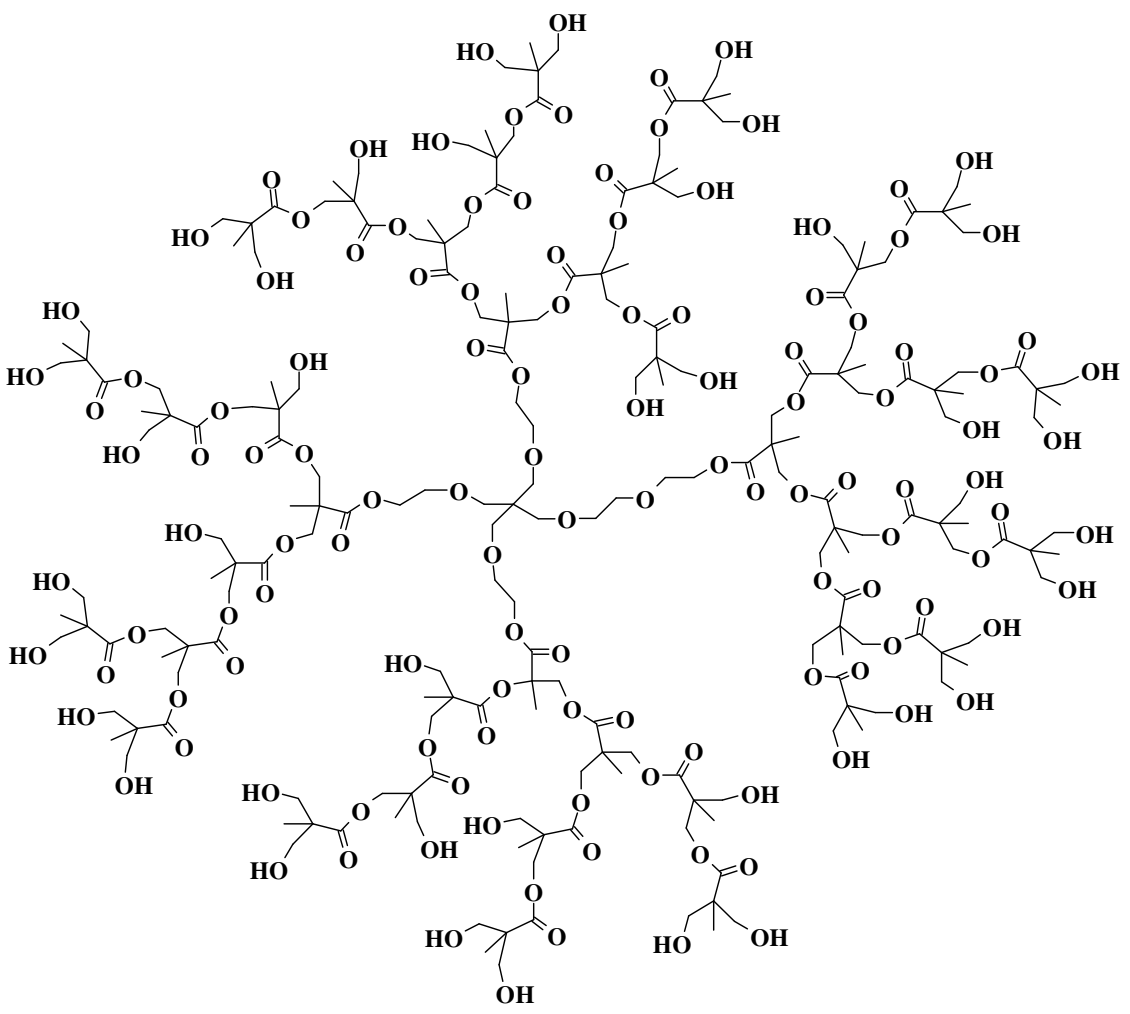

Fig. 1. Structure of the monomers used for the PU network synthesis.
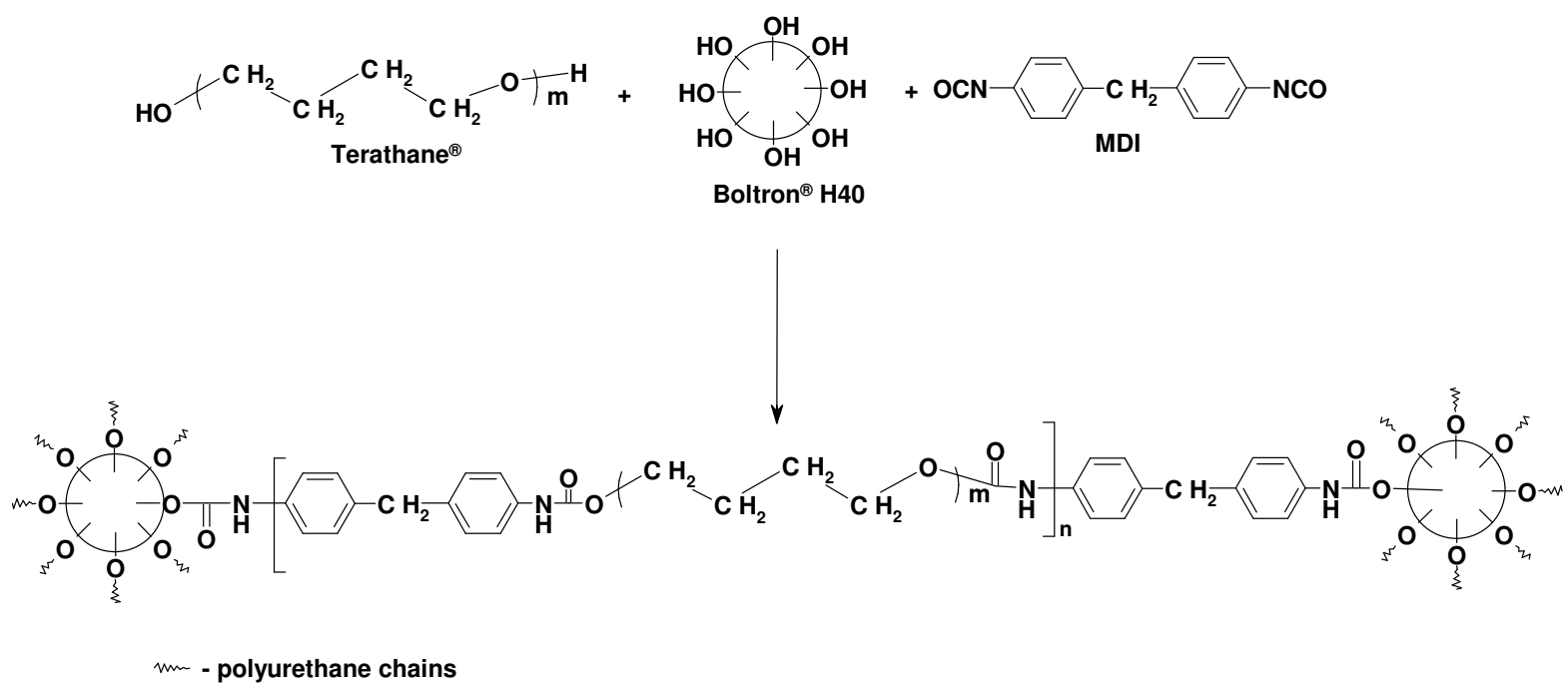

Fig. 2. Diagram of the PU network synthesis 


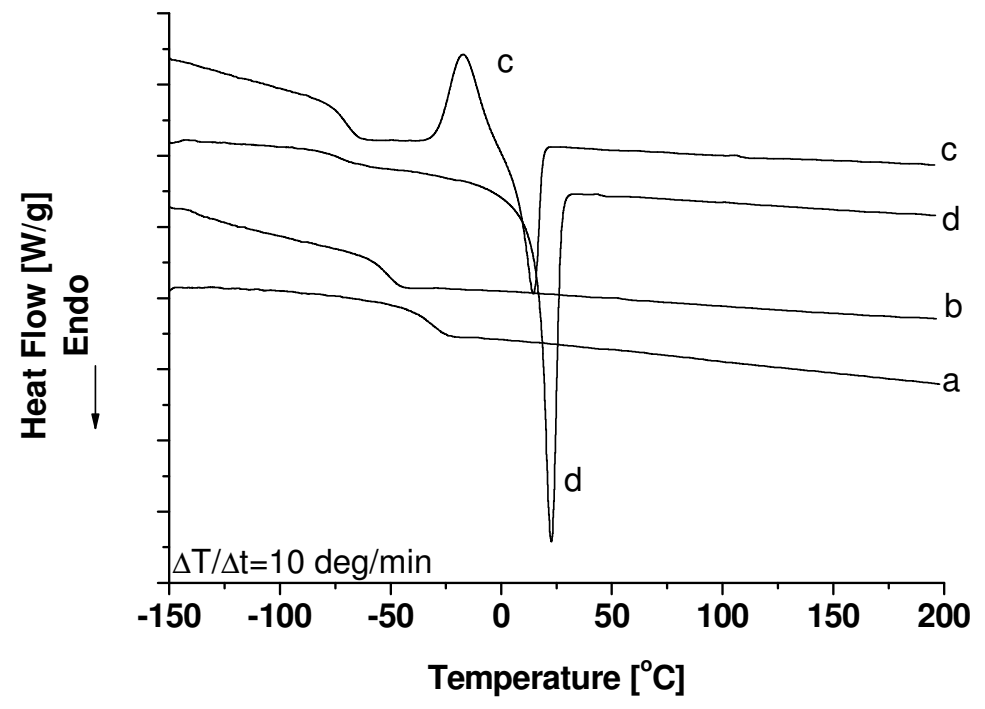

Fig. 3. DSC spectra (second scans) for the PU systems with different lengths of macrodiol: a) 20-T650, b) 20-T1000, c) 20-T2000 and d) 20-T2900. 

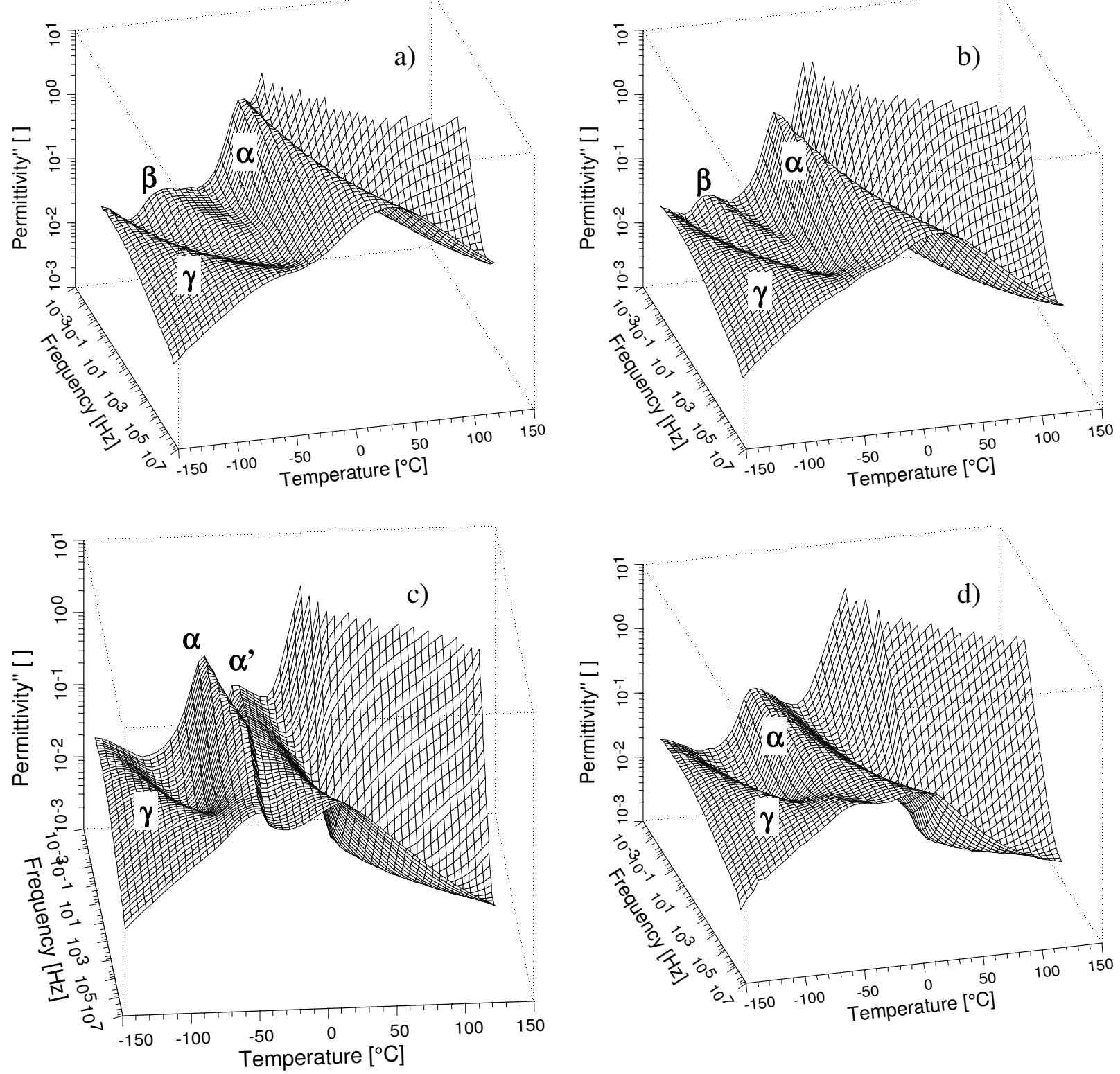

Fig. 4. Frequency and temperature dependencies of the dielectric permittivity imaginary part for the PU networks based on macrodiol with different lengths, but constant $n=20$ : a) 20-T650, b) 20-T1000, c) 20-T2000 and d) 20-T2900. 


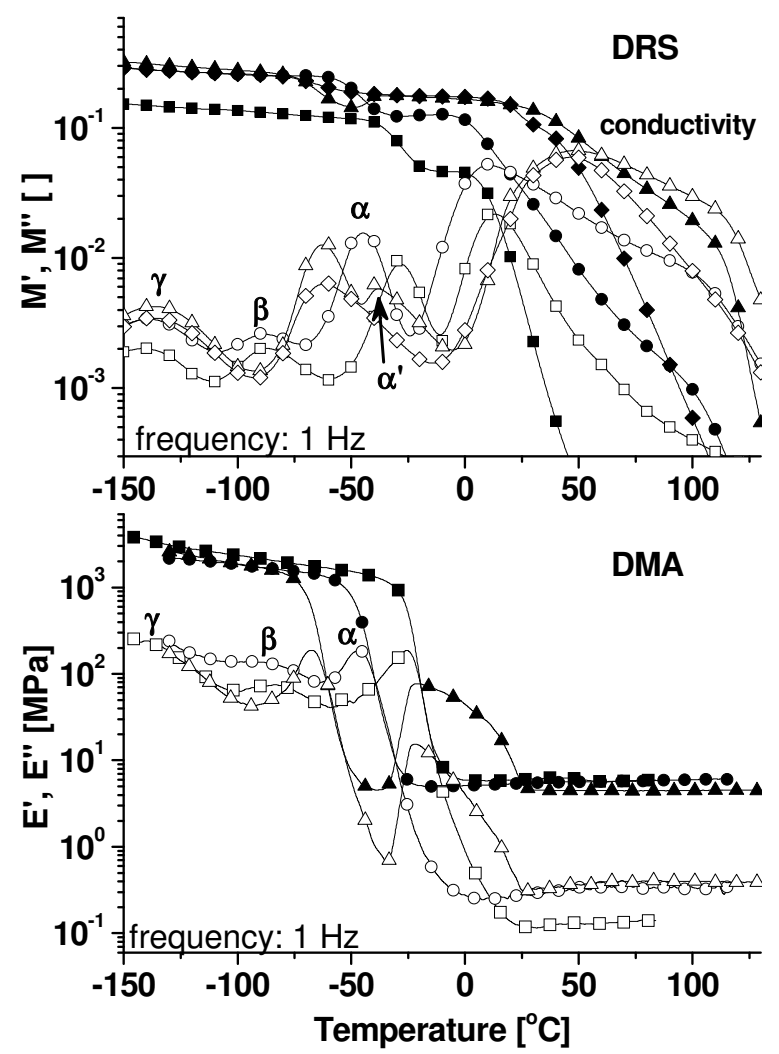

Fig. 5. DRS and DMA spectra for the PU networks based on macrodiols with different molecular weight but constant $n=20$ : 20-T650 (घ, $\square), 20-T 1000(\bullet, O), 20-T 2000(\boldsymbol{\Delta}, \triangle)$ and $20-\mathrm{T} 2900(\bullet, \diamond)$. Full points - real part, open points - imaginary part of the moduli.

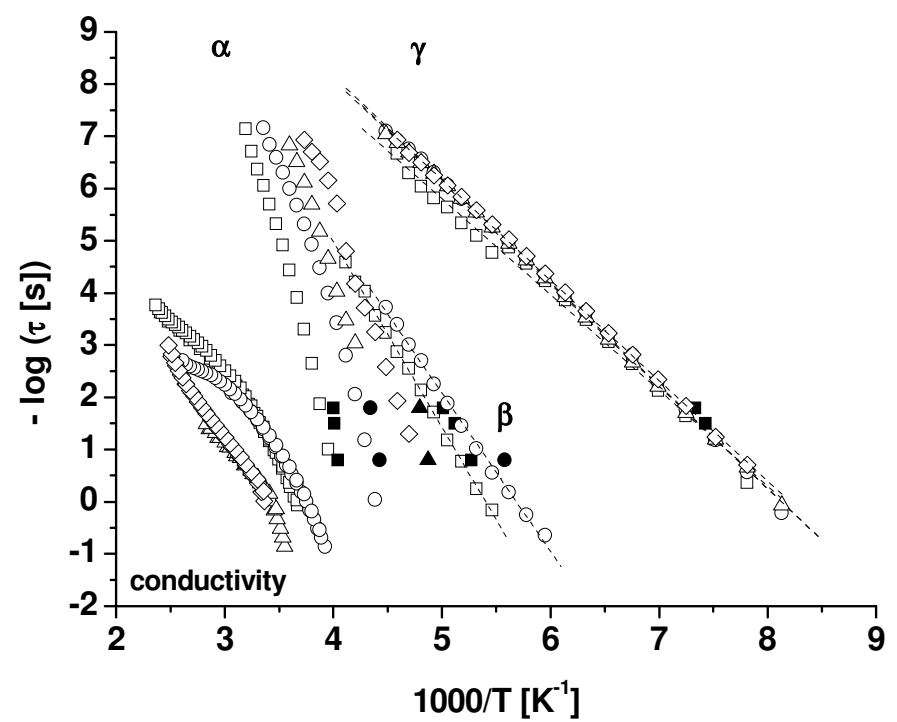

Fig. 6. Activation map for relaxation process in the PU networks based on macrodiols with different molecular weight but constant $n=20$ : 20-T650 ( $\square, \boldsymbol{\square}), 20-\mathrm{T} 1000(\bigcirc, \bullet), 20-\mathrm{T} 2000$ $(\triangle, \mathbf{\Delta}), 20-\mathrm{T} 2900(\diamond)$. Open points - DRS; full points - DMA. 


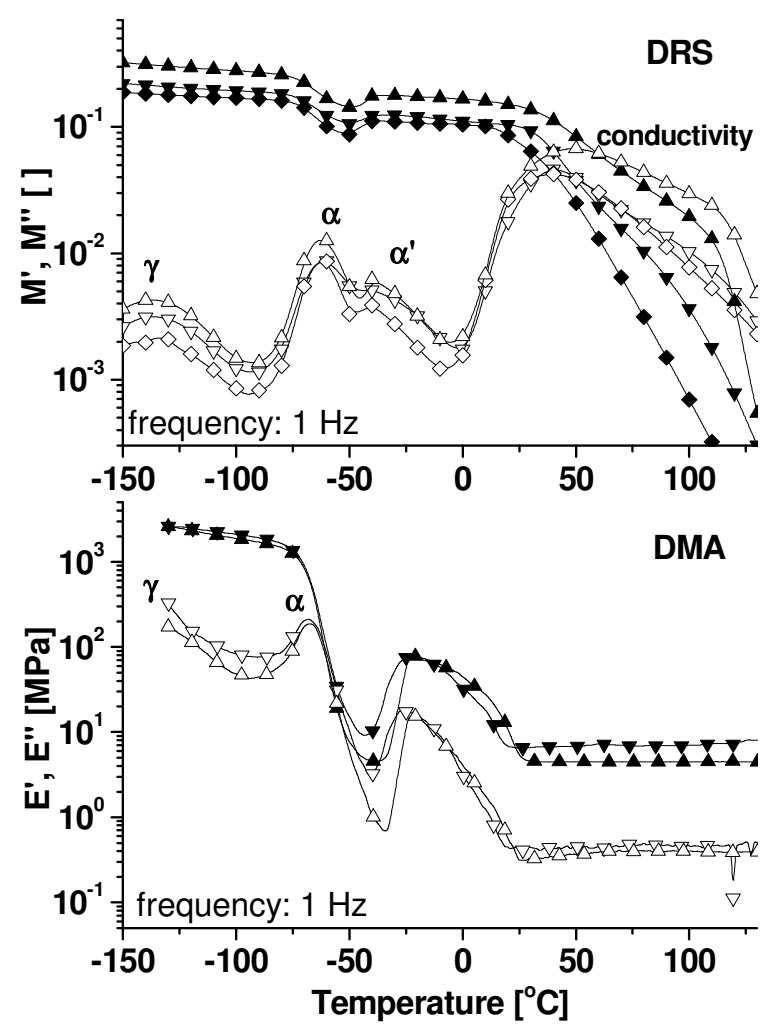

Fig. 7. DRS and DMA spectra for PU networks based on the same macrodiol Terathane ${ }^{\circledR} 2000$ but with different numbers of repeating units $n$ : 4-T2000 $(\boldsymbol{\nabla}, \nabla), 10-\mathrm{T} 2000(\bullet, \diamond)$ and 20-T2000 $(\boldsymbol{\Delta}, \triangle)$. Full points - real part, open points - imaginary part of the moduli.

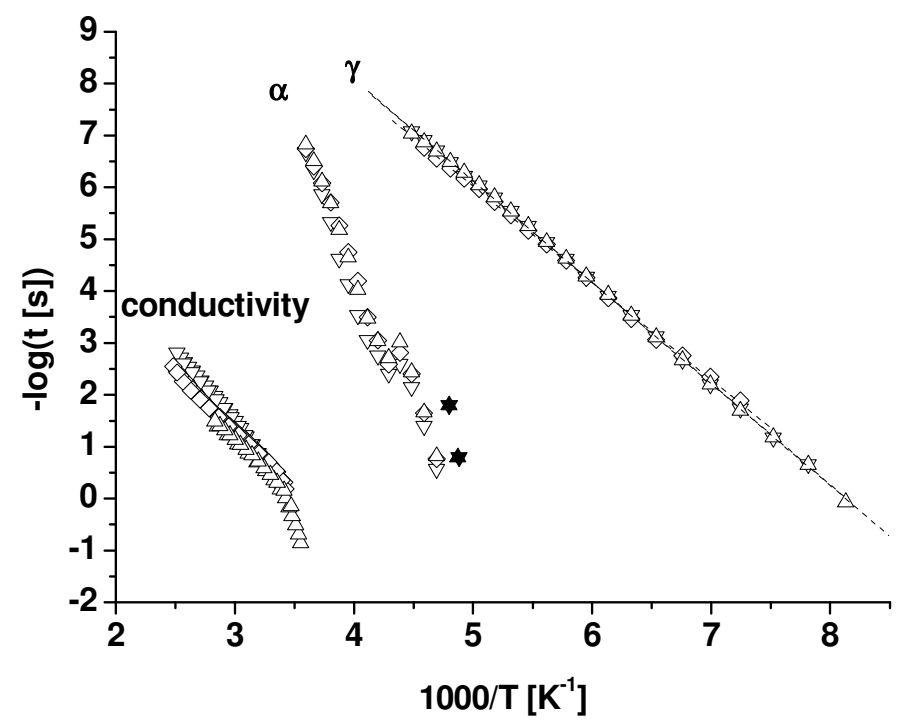

Fig. 8. Activation map for PU networks based on the same macrodiol Terathane ${ }^{\circledR} 2000$ but with different numbers of repeating units $n$ : 4-T2000 $(\nabla, \nabla), 10-\mathrm{T} 2000(\diamond, \diamond)$ and 20-T2000 $(\boldsymbol{\Lambda}, \triangle)$. Open points - DRS; full points - DMA. 


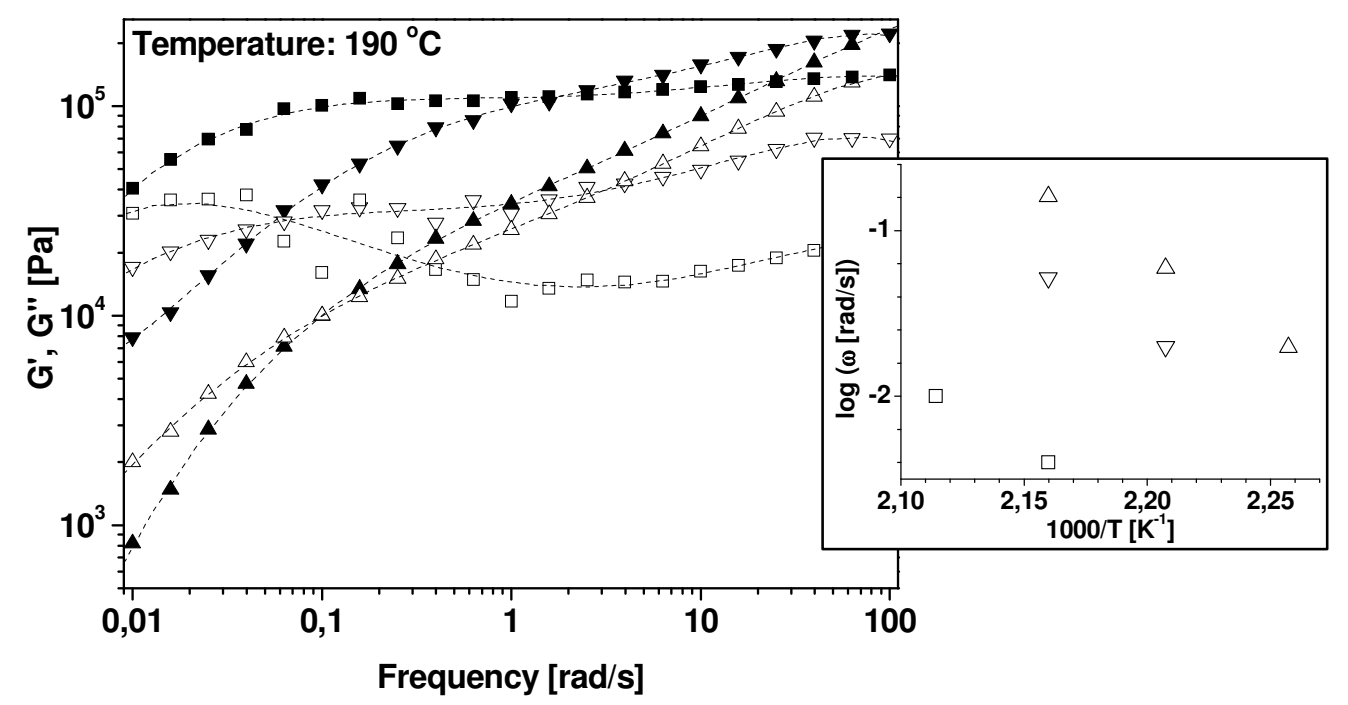

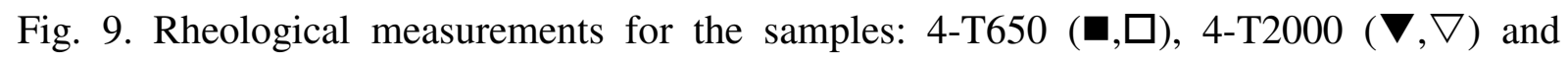
20-T2000 $(\boldsymbol{\Delta}, \triangle)$. Full points - real part, open points - imaginary part of the shear modulus $G$. Inset diagram shows the frequency-temperature dependence of the flowing points.

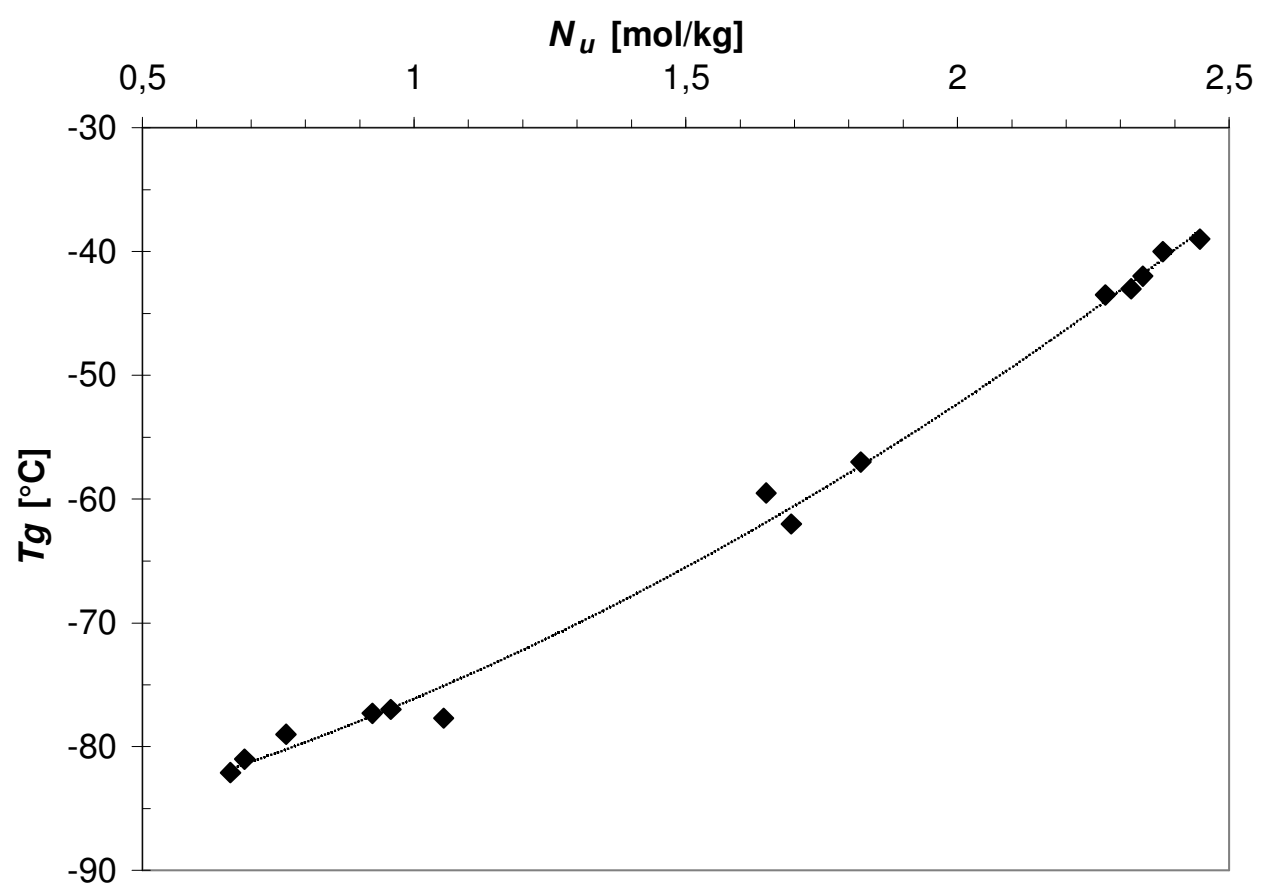

Fig. 10. Dependence of $T_{g}$ (determined from the second DSC scans) versus the weight concentration of the urethane groups $N_{u}$ determined for the PU networks described in this work and in ref. 17 (solid line: empirical $2^{\text {nd }}$ power law $T_{g}=-89.5+8.22 N_{u}+5.20 N_{u}{ }^{2}$ ). 